\title{
Multifractal characteristics of titanium nitride thin films
}

\author{
ŞTefan Ţălu ${ }^{1 *}$, Sebastian Stach $^{2}$, Shahoo VAledbagi $^{3}$, Reza Bavadi $^{3}$, \\ S. Mohammad Elahi ${ }^{3}$, Mihai ŢăLU ${ }^{4}$ \\ ${ }^{1}$ Technical University of Cluj-Napoca, Faculty of Mechanical Engineering, Department of AET, Discipline of Descriptive \\ Geometry and Engineering Graphics, 103 - 105 B-dul Muncii St., Cluj-Napoca 400641, Cluj, Romania \\ ${ }^{2}$ University of Silesia, Faculty of Computer Science and Materials Science, Institute of Informatics, Department of \\ Biomedical Computer Systems, Będzińska 39, 41-205 Sosnowiec, Poland \\ ${ }^{3}$ Islamic Azad University, Plasma Physics Research Center, Science and Research Branch, P.O. Box 14665-678, Tehran, Iran \\ ${ }^{4}$ University of Craiova, Faculty of Mechanical Engineering, Department of Applied Mechanics, 165 Calea Bucureşti St., \\ Craiova, 200585, Dolj, Romania
}

\begin{abstract}
The study presents a multi-scale microstructural characterization of three-dimensional (3-D) micro-textured surface of titanium nitride (TiN) thin films prepared by reactive DC magnetron sputtering in correlation with substrate temperature variation. Topographical characterization of the surfaces, obtained by atomic force microscopy (AFM) analysis, was realized by an innovative multifractal method which may be applied for AFM data. The surface micromorphology demonstrates that the multifractal geometry of TiN thin films can be characterized at nanometer scale by the generalized dimensions $\mathrm{D}_{\mathrm{q}}$ and the singularity spectrum $f(\alpha)$. Furthermore, to improve the 3-D surface characterization according with ISO 25178-2:2012, the most relevant 3-D surface roughness parameters were calculated. To quantify the 3-D nanostructure surface of TiN thin films a multifractal approach was developed and validated, which can be used for the characterization of topographical changes due to the substrate temperature variation.
\end{abstract}

Keywords: atomic force microscopy; DC magnetron sputtering; multifractal analysis; surface roughness; titanium nitride (TiN) thin film

(C) Wroclaw University of Technology.

\section{Introduction}

New materials and/or new thin film deposition technologies are broadly used in technological applications in microelectronics, optoelectronics, biomedical engineering and microsystems [1-4].

Titanium nitride (TiN) is an extremely hard ceramic material, often used as a coating on titanium alloys, steel, carbide, and aluminium components to improve the substrate surface properties. TiN has an ideal combination of hardness, toughness, adhesion and inertness. It is used in the microelectronics industry as a diffusion barrier material, and to the hard and protective coatings on mechanical tools and decorative coatings $[5,6]$. The advantages of TiN thin film coatings include high

*E-mail: stefan_ta@yahoo.com hardness and adhesion, good ductility, excellent lubricity, high chemical stability and tough resistance to wear, corrosion and temperature. The relationships between the TiN processing parameters, the film structure and properties were determined in different types of studies [7, 8]. The mechanical properties of TiN film are correlated with the fine grains, the crystallographic orientation, high compressive residual stresses or the dense defectfree structure of the coatings. Also, the resistivity of TiN thin films is correlated with thickness and the packing factor for all coating angles (the angle between specimen surface and the evaporating source) $[5,9]$. TiN coatings are generally prepared by PVD (Physical Vapor Deposition) techniques. Direct-current (DC) magnetron sputtering is one of the dominant methods for thin film fabrication, that can be applied also for the preparation of TiN thin films [2, 10-12]. 
Hofmann [13] proposed a systematic study of nitrides formation by sputtering titanium targets in $\mathrm{Ar} / \mathrm{N}_{2}$ mixtures. Mientus and Ellmer [14] investigated the discharge characteristics of a series of elemental targets (aluminium, silicon, titanium, chromium, indium, tin) during reactive magnetron sputtering in $\mathrm{Ar} / \mathrm{N}_{2}$ mixtures. The authors concluded that the deposition rate decreases when nitrogen partial pressure increases [14]. In this study, our particular aspect relates to improving material characterization of 3-D surface roughness of TiN thin films prepared by reactive DC magnetron sputtering, through atomic force microscopy (AFM) and multifractal analysis. The multifractal modeling was originally developed for the study of the 3-D surface roughness to characterize the spatial inhomogeneity of fractal patterns.

\section{Materials and methods}

\subsection{Materials}

The TiN thin film was deposited on a p-type silicon (100) substrate by reactive DC magnetron sputtering technique in an $\mathrm{Ar}+\mathrm{N}_{2}$ atmosphere. Ar and nitrogen gases (with high purity: $99.999 \%$ ) and with the ratio $\mathrm{Ar}(97 \%)$ and $\mathrm{N}_{2}(3 \%)$ by volume were used as reactive sputtering gases. This system consisted of planar Ti metal $(99.99 \%$ purity) with $5 \mathrm{~cm}$ diameter. The average distance between the target and the wafer was $3 \mathrm{~cm}$. A rotary pump (ALCATEL) and defusing pumps were used to evacuate the growth chamber up to a pressure of $1 \times 10^{-3} \mathrm{~Pa}$. Then, the reactive sputtering gases were introduced into the sputter chamber.

During the growth of all samples the pressure in the sputter chamber was constant, with a value of $2.66 \mathrm{~Pa}$, at a current density of $10 \mathrm{~mA} / \mathrm{cm}^{2}$. The films were deposited in three states at four different substrate temperatures: $473 \mathrm{~K}, 573 \mathrm{~K}, 673 \mathrm{~K}$, and $773 \mathrm{~K}$, respectively, at the same deposition time of $120 \mathrm{~min}$.

\subsection{Methods}

An atomic force microscope (AFM) (Digital Instruments, Mod. Nanoscope E, USA) and its own software was used in contact mode to image the samples. These measurements were performed in air (ex-situ) using silicon nitride AFM tips (Digital Instruments), in the same room, at room temperature $(297 \pm 1 \mathrm{~K})$, ambient pressure and $(50 \pm 1 \%)$ relative humidity. The measurements were repeated for three times for each sample on different reference areas. The resolution of the AFM images was 256 pixels by 256 pixels. The Digital Surf MountainsMap® Premium software version 7 [15] was used for surface characterization of the AFM images, for estimation of areal surface texture parameters in accordance with ISO 25178-2:2012 [16].

\subsection{Multifractal analysis of the 3-D sur- face texture}

Multifractal analysis is a useful method, based on the multifractal theory that can be applied to characterize the spatial inhomogeneity of both theoretical and experimental fractal patterns [17-21]. Multifractal analysis has clearly an advantage compared with standard statistical approaches because its parameters are independent over a range of scales as well as that no assumption is required about the data following any specific distribution. Also, it gives information about both local and global properties of the analyzed datasets [22].

The fundamental characteristics of multifractal distributions are: a) the generalized fractal dimensions function $D_{q}$, where $q$ is a real parameter within the domain $[-\infty,+\infty]$ that indicates the order of the moment of the measure; and b) the singularity spectrum $f(\alpha)$, where $\alpha$ is named Hölder or singularity exponent that quantifies the strength of the measure singularities [20]. The multifractal spectrum can be calculated explicitly through several methods [22-26].

The generalized dimensions, $D_{q}$ for $q=0$, $\mathrm{q}=1$ and $\mathrm{q}=2$, are referred as the capacity (or box-counting), the information entropy and correlation dimensions, respectively. The function $\mathrm{D}_{\mathrm{q}}$ is a linear function of $\mathrm{q}$ for monofractal sets, while for multifractal sets $D_{q}$ is a non-linear function of $q$. Any asymmetry of the function of $\mathrm{D}_{\mathrm{q}}$ is an indicator of an asymmetrical probability distribution [27]. The computed dimensions, $\mathrm{D}_{0}, \mathrm{D}_{1}$ and $\mathrm{D}_{2}$ for 
multifractal sets, are different, satisfying the relation: $\mathrm{D}_{0}>\mathrm{D}_{1}>\mathrm{D}_{2}$.

On the other hand, the $\mathrm{D}(\mathrm{q})$ spectrum and the singularity spectrum $\mathrm{f}(\alpha)$ are connected via a Legendre transform as [23]:

$$
f(\alpha(q))=q \alpha(q)-\tau(q)
$$

where $\alpha(q)$ represents Hölder exponents of the $\mathrm{q}$-th order moment and $\tau(\mathrm{q})$ is the mass correlation exponent of the q-th order. The entire spectrum of generalized fractal dimensions is also included in the plot $f(\alpha)$. The singularity spectrum $\mathrm{f}(\alpha(\mathrm{q}))$ takes its maximum value for $\mathrm{q}=0$ and usually has a parabolic shape around this point. The spectrum width or degree of multifractality is defined as $\Delta \alpha=\alpha_{\max }-\alpha_{\min }$ and a broader spectrum of $\Delta \alpha$ is associated with a higher degree of multifractality. Another quantitative measurement is the spectrum arms' height difference defined as: $\Delta \mathrm{f}=\mathrm{f}\left(\alpha_{\min }\right)-\mathrm{f}\left(\alpha_{\max }\right)$. If $\Delta \mathrm{f}<0$, the fragments described by the low probability value predominate; whereas for $\Delta \mathrm{f}>0$ the fragments described by the high probability value predominate [28].

In our study, the multifractal analysis of the AFM files was performed for each region of interest (ROI), using the box counting method. The analysis was based on the original algorithm that has been previously described in detail in the literature $[29,30]$.

The 3-D surface topography of thin films is proven to possess only a statistical self-similarity, which takes place only in the restricted range of the spatial scales when maintaining the characteristics of continuity, non-differentiability and selfsimilarity of the structure [18,31-33].

Different investigators highlighted a correlation between the different surface roughness parameters and the multifractal spectrum $f(\alpha)$ [18-21]

\subsection{Statistical analysis}

Statistical analyses were performed using the GraphPad InStat version 3.20 computer software package (GraphPad, San Diego, CA, USA) [34]. Comparisons among different areas within the same sample were performed using independent samples T-test. When statistical significance was found, the difference between two groups was further compared using the Mann-Whitney $U$ test. Differences with a $\mathrm{P}$ value of 0.05 or less were considered statistically significant. The average $D_{q}$ results were expressed as mean value and standard deviation.

\section{Results}

One set of representative 3D topographic AFM images of layers grown at different temperatures, in perspective view, for scanning square area of $1 \mu \mathrm{m}$ $\times 1 \mu \mathrm{m}$, are shown in Fig. 1: (a) $473 \mathrm{~K}$, (b) $573 \mathrm{~K}$, (c) $673 \mathrm{~K}$, and (d) $773 \mathrm{~K}$.

The depth histograms associated with Fig. 1 that enable us to observe the density of the distribution of the data points on the surface, are shown in Fig. 2. The vertical axis is graduated in depths, while the horizontal axis is graduated in $\%$ of the whole population. The Abbott-Firestone curve is overlaid in red. This function is the cumulating function of the amplitude distribution function. The horizontal axis represents the bearing ratio (in \%), and the vertical axis represents the depths (in the measurement unit).

To illustrate how the multifractality can be quantified, the multifractal singularity spectra $f(\alpha)$ calculated for all microstructures of Fig. 1 in the range $-10 \leqslant \mathrm{q} \leqslant 10$ for successive 1.0 steps, are shown altogether in Fig. 3.

The values resulting from the multifractal analysis (based on the box-counting method) and the corresponding values of generalized fractal dimensions $\mathrm{D}_{\mathrm{q}}$ are listed in Table 1 .

Table 2 contains the areal surface texture parameters of the AFM images, according with ISO 25178-2:2012 [16].

\section{Discussion}

The 3-D surface topographies of (TiN) thin films prepared by reactive DC magnetron sputtering are geometrically complex, with complicated patterns and shapes, and can be described, both locally and globally, by means of the multifractal analysis. 
Table 1. The generalized dimensions $\mathrm{D}_{\mathrm{q}}$ for $\mathrm{q}=0,1,2$, all with average \pm standard deviation, for the $A F M$ images of TiN layers nanostructures grown at: (a) $473 \mathrm{~K}$, (b) $573 \mathrm{~K}$, (c) $673 \mathrm{~K}$, and (d) $773 \mathrm{~K}$. $\Delta \alpha$ is the multifractal width spectrum $\left(\Delta \alpha=\alpha_{\max }-\alpha_{\min }\right) . \Delta \mathrm{f}$ is the spectrum arms' heights difference $\Delta \mathrm{f}=\mathrm{f}\left(\alpha_{\min }\right)-\mathrm{f}\left(\alpha_{\max }\right)$. Scanning square areas of $1 \times 1 \mu \mathrm{m}^{2}$. Statistically significant difference for all values: $\mathrm{P}<0.05$.

\begin{tabular}{ccccc}
\hline \multirow{2}{*}{ The multifractal parameters } & \multicolumn{4}{c}{ Samples of grown TiN layers nanostructures } \\
\cline { 2 - 5 } & $2.0000 \pm 0.0001$ & $2.0000 \pm 0.0001$ & $2.0000 \pm 0.0001$ & $2.0000 \pm 0.0001$ \\
\hline \hline $\mathrm{D}_{0}$ & $1.9976 \pm 0.0001$ & $1.9227 \pm 0.0001$ & $1.9110 \pm 0.0007$ & $1.9033 \pm 0.0002$ \\
$\mathrm{D}_{1}$ & $1.9879 \pm 0.0004$ & $1.6387 \pm 0.0004$ & $1.6261 \pm 0.0003$ & $1.6068 \pm 0.0004$ \\
$\mathrm{D}_{2}$ & $2.0020 \pm 0.0008$ & $2.0669 \pm 0.0127$ & $2.0773 \pm 0.0046$ & $2.0888 \pm 0.0052$ \\
$\alpha_{0}$ & $1.9976 \pm 0.0010$ & $1.9227 \pm 0.0154$ & $1.9110 \pm 0.0057$ & $1.9033 \pm 0.0060$ \\
$\alpha_{1}$ & $1.9912 \pm 0.0041$ & $1.7340 \pm 0.0493$ & $1.7195 \pm 0.0170$ & $1.7045 \pm 0.0136$ \\
$\alpha_{2}$ & $2.0162 \pm 0.0041$ & $2.2810 \pm 0.0056$ & $2.2962 \pm 0.0062$ & $2.3603 \pm 0.0122$ \\
$\alpha_{\max }$ & $1.8139 \pm 0.0396$ & $1.4068 \pm 0.0260$ & $1.3849 \pm 0.0113$ & $1.3527 \pm 0.0126$ \\
$\alpha_{\min }$ & 0.2023 & 0.8742 & 0.9113 & 1.0076 \\
$\Delta \alpha=\alpha_{\max }-\alpha_{\min }$ & $2.0000 \pm 0.0001$ & $2.0000 \pm 0.0001$ & $2.0000 \pm 0.0001$ & $2.0000 \pm 0.0001$ \\
$\mathrm{f}_{0}$ & $1.9976 \pm 0.0010$ & $1.9227 \pm 0.0154$ & $1.9110 \pm 0.0057$ & $1.9032 \pm 0.0060$ \\
$\mathrm{f}_{1}$ & $1.9878 \pm 0.0058$ & $1.6386 \pm 0.0653$ & $1.6261 \pm 0.0223$ & $1.6068 \pm 0.0165$ \\
$\mathrm{f}_{2}$ & $0.8479 \pm 0.1456$ & $0.4380 \pm 0.0720$ & $0.3133 \pm 0.1860$ & $0.3436 \pm 0.0465$ \\
$\mathrm{f}\left(\alpha_{\min }\right)$ & $1.9517 \pm 0.0065$ & $1.5530 \pm 0.0831$ & $1.5626 \pm 0.0621$ & $1.4880 \pm 0.0793$ \\
$\mathrm{f}\left(\alpha_{\max }\right)$ & -1.1038 & -1.1150 & -1.2493 & -1.1444 \\
$\Delta \mathrm{f}=\mathrm{f}\left(\alpha_{\min }\right)-\mathrm{f}\left(\alpha_{\max }\right)$ & & & &
\end{tabular}

In all AFM images, it can be seen that due to the grow process, the 3-D surface of the samples are covered by nanoasperities with different distributions of asperity height and density, and with different shapes of asperity apex (Fig. 1). This surface pattern is a first confirmation of the surface geometrical multifractal nature.

In the multifractal analysis based on boxcounting method, the computed spectrum of fractal dimensions reveals the heterogeneity in the distribution. In all results, the relation $D_{0}>D_{1}>D_{2}$ is verified, which indicates that the (TiN) thin films have the 3-D surface roughness with multifractal scaling property.

All the $f(\alpha)$ graphs are asymmetric with respect to the variable $\alpha$. Multifractal spectra $f(\alpha)$ show that the higher the substrate temperature, the wider is the multifractal width spectrum $\left(\Delta \alpha=\alpha_{\max }-\alpha_{\min }\right)$ with $\Delta \alpha>0$. In the formalism of multifractals, $\alpha_{\min }$ is related to the maximum probability measure, while $\alpha_{\max }$ is related to the minimum probability measure. Thus, the multifractal width spectrum $\Delta \alpha$ can be used to describe the range of the probabilities.
For all the samples the left shoulder of the multifractal singularity spectrum $f(\alpha)$ is much longer than the right shoulder. When the multifractal spectrum is wider than another it indicates that we need more fractal dimensions in order to describe the multifractal structure. It can be seen that the shapes of the multifractal spectra $f(\alpha)$ versus $\alpha$ are different and are all mainly hook-like to the left. The left shoulder of the multifractal singularity spectrum $\mathrm{f}(\alpha)$ for the surface obtained at $773 \mathrm{~K}$ is much longer than those of the samples obtained at $673 \mathrm{~K}$, $573 \mathrm{~K}$ and $473 \mathrm{~K}$, respectively. The left arm of the multifractal spectrum corresponds to strongly irregular areas, defined by a high dimension value, whereas the right arm of the multifractal spectrum is associated with flat areas, being characteristic of large convex and concave surfaces [28].

The most regular surface is obtained for $473 \mathrm{~K}$ with a minimum value of $\Delta \alpha=0.2023$.

$\Delta \mathrm{f}=\mathrm{f}\left(\alpha_{\min }\right)-\mathrm{f}\left(\alpha_{\max }\right)$ corresponds to the ratio of the number of the maximum probability and that of the minimum one. For all the samples the spectrum arms' height difference $\Delta f<0$, and it falls within the range of -1.25 to -1.10 , 
Table 2. The areal surface texture parameters of the TiN layers nanostructures grown at: (a) $473 \mathrm{~K}$, (b) $573 \mathrm{~K}$, (c) $673 \mathrm{~K}$, and (d) $773 \mathrm{~K}$, for scanning square areas of $1 \times 1 \mu \mathrm{m}^{2}$, according with ISO 25178-2:2012. Statistically significant difference for all values: $\mathrm{P}<0.05$.

\begin{tabular}{|c|c|c|c|c|c|}
\hline \multirow{2}{*}{ The statistical parameters } & \multirow{2}{*}{ Symbol } & \multicolumn{4}{|c|}{ Samples at temperature } \\
\hline & & $473 \mathrm{~K}$ & $573 \mathrm{~K}$ & $673 \mathrm{~K}$ & $773 \mathrm{~K}$ \\
\hline \multicolumn{6}{|l|}{ Height parameters } \\
\hline Root mean square height & $\mathrm{Sq}[\mathrm{nm}]$ & 0.616 & 2.71 & 4.51 & 4.82 \\
\hline Skewness & Ssk $[-]$ & 0.213 & -0.142 & -0.006 & -0.249 \\
\hline Kurtosis & Sku [-] & 3.15 & 4.02 & 3.06 & 2.83 \\
\hline Maximum peak height & $\mathrm{Sp}[\mathrm{nm}]$ & 2.90 & 13.1 & 17.7 & 14.6 \\
\hline Maximum pit height & $\mathrm{Sv}[\mathrm{nm}]$ & 2.10 & 16.9 & 18.3 & 17.9 \\
\hline Maximum height & $\mathrm{Sz}[\mathrm{nm}]$ & 5.01 & 30.1 & 36.0 & 32.5 \\
\hline Arithmetic mean height & $\mathrm{Sa}[\mathrm{nm}]$ & 0.491 & 2.09 & 3.58 & 3.89 \\
\hline \multicolumn{6}{|l|}{ Functional parameters } \\
\hline Areal material ratio & Smr [\%] & 100 & 100 & 100 & 100 \\
\hline Inverse areal material ratio & $\mathrm{Smc}[\mathrm{nm}]$ & 0.802 & 3.30 & 5.87 & 6.18 \\
\hline $\begin{array}{l}\text { Extreme peak height } \\
\text { Spatial parameters }\end{array}$ & Sxp [nm] & 1.13 & 5.54 & 8.79 & 10.0 \\
\hline Auto-correlation length & Sal $[\mu \mathrm{m}]$ & 0.0262 & 0.0153 & 0.0324 & 0.0287 \\
\hline Texture-aspect ratio & $\operatorname{Str}[-]$ & 0.637 & 0.417 & 0.675 & 0.773 \\
\hline Texture direction & $\operatorname{Std}\left[{ }^{\circ}\right]$ & $177^{\circ}$ & $5.75^{\circ}$ & $12.3^{\circ}$ & $12.8^{\circ}$ \\
\hline \multicolumn{6}{|l|}{ Hybrid parameters } \\
\hline Root mean square gradient & Sdq [-] & 0.0634 & 0.414 & 0.394 & 0.468 \\
\hline Developed interfacial area ratio & $\operatorname{Sdr}[\%]$ & 0.200 & 7.32 & 6.80 & 9.46 \\
\hline \multicolumn{6}{|l|}{ Functional parameters (Volume) } \\
\hline Material volume & $\mathrm{Vm}\left[\mu \mathrm{m}^{3} / \mu \mathrm{m}^{2}\right]$ & $3.18 \mathrm{e}-005$ & 0.00013 & 0.00020 & 0.00017 \\
\hline Void volume & $\mathrm{Vv}\left[\mu \mathrm{m}^{3} / \mu \mathrm{m}^{2}\right]$ & 0.000834 & 0.00344 & 0.00607 & 0.00635 \\
\hline Peak material volume & $\operatorname{Vmp}\left[\mu \mathrm{m}^{3} / \mu \mathrm{m}^{2}\right]$ & $3.18 \mathrm{e}-005$ & 0.00013 & 0.00020 & 0.00017 \\
\hline Core material volume & $\operatorname{Vmc}\left[\mu \mathrm{m}^{3} / \mu \mathrm{m}^{2}\right]$ & 0.000548 & 0.00233 & 0.00406 & 0.00448 \\
\hline Core void volume & $\mathrm{Vvc}\left[\mu \mathrm{m}^{3} / \mu \mathrm{m}^{2}\right]$ & 0.000769 & 0.00310 & 0.00556 & 0.00576 \\
\hline Pit void volume & $\operatorname{Vvv}\left[\mu \mathrm{m}^{3} / \mu \mathrm{m}^{2}\right]$ & $6.47 \mathrm{e}-005$ & 0.00033 & 0.00051 & 0.00058 \\
\hline \multicolumn{6}{|l|}{ Feature parameters } \\
\hline Density of peaks & $\operatorname{Spd}\left[1 / \mu \mathrm{m}^{2}\right]$ & 133 & 231 & 91.7 & 143 \\
\hline Arithmetic mean peak curvature & $\mathrm{Spc}[1 / \mu \mathrm{m}]$ & 20.7 & 131 & 65.9 & 67.0 \\
\hline Ten point height & $\mathrm{S} 10 \mathrm{z}[\mathrm{nm}]$ & 3.25 & 20.0 & 22.3 & 23.7 \\
\hline Five point peak height & $\mathrm{S} 5 \mathrm{p}[\mathrm{nm}]$ & 1.88 & 9.12 & 10.7 & 11.0 \\
\hline Five point pit height & $\mathrm{S} 5 \mathrm{v}[\mathrm{nm}]$ & 1.37 & 10.9 & 11.7 & 12.8 \\
\hline Mean dale area & $\mathrm{Sda}\left[\mu \mathrm{m}^{2}\right]$ & 0.00579 & 0.00383 & 0.00755 & 0.00555 \\
\hline Mean hill area & Sha $\left[\mu \mathrm{m}^{2}\right]$ & 0.00619 & 0.00404 & 0.0106 & 0.00713 \\
\hline Mean dale volume & $\operatorname{Sdv}\left[\mu \mathrm{m}^{3}\right]$ & $3.3 \mathrm{e}-007$ & $1.4 \mathrm{e}-006$ & $3.2 \mathrm{e}-006$ & $2.0 \mathrm{e}-006$ \\
\hline Mean hill volume & $\operatorname{Shv}\left[\mu \mathrm{m}^{3}\right]$ & $5.18 \mathrm{e}-007$ & $1.7 \mathrm{e}-006$ & $9.7 \mathrm{e}-006$ & $5.2 \mathrm{e}-006$ \\
\hline
\end{tabular}




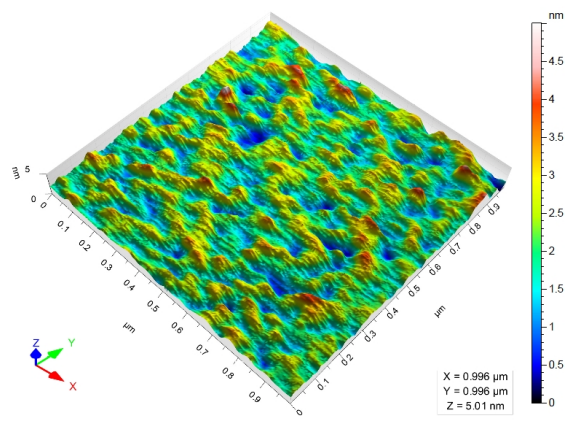

(a)

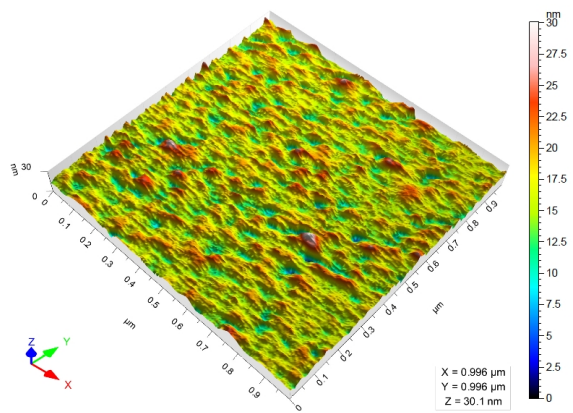

(b)

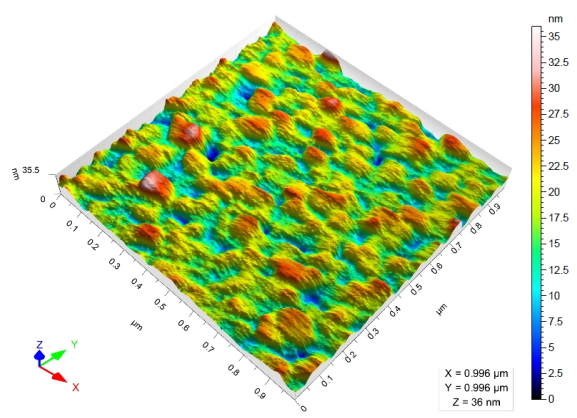

(c)

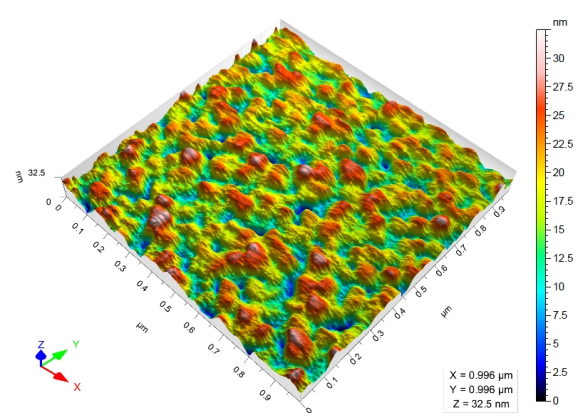

(d)

Fig. 1. One set of representative 3-D topographic AFM images of TiN grown layers, obtained at: (a) $473 \mathrm{~K}$, (b) $573 \mathrm{~K}$, (c) $673 \mathrm{~K}$, and (d) $773 \mathrm{~K}$ in perspective view, for scanning square area of $1 \mu \mathrm{m} \times 1 \mu \mathrm{m}$.

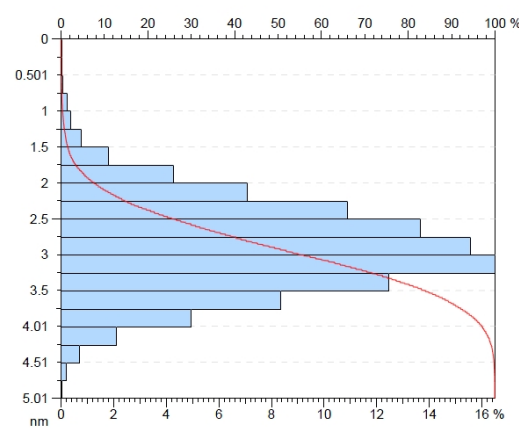

(a)

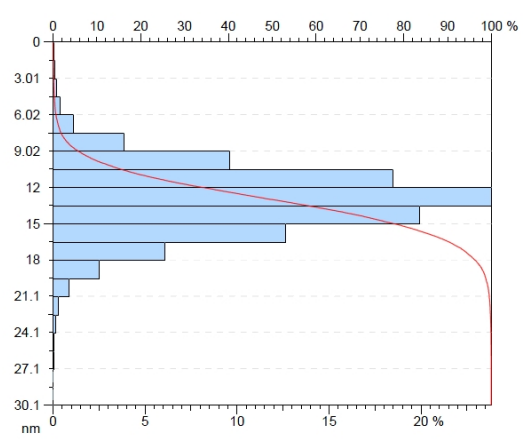

(b)

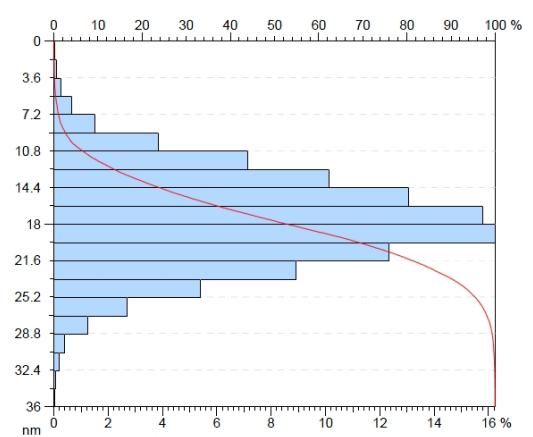

(c)

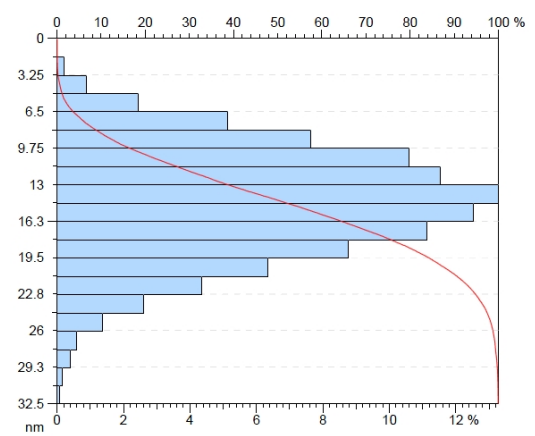

(d)

Fig. 2. The depth histograms of TiN grown layers, obtained at: (a) $473 \mathrm{~K}$, (b) $573 \mathrm{~K}$, (c) $673 \mathrm{~K}$, and (d) $773 \mathrm{~K}$ for scanning square area of $1 \mu \mathrm{m} \times 1 \mu \mathrm{m}$. 
depending upon the samples temperature; that imply the fragments, where the low probability values predominate. The value of $\Delta \mathrm{f}$ decreases with the substrate temperature variation from -1.1038 (at $473 \mathrm{~K}$ ) to -1.1150 (at $573 \mathrm{~K}$ ). From the lowest value of -1.2493 (at $673 \mathrm{~K}$ ) it increases to -1.1444 at $773 \mathrm{~K}$ (Fig. 3).

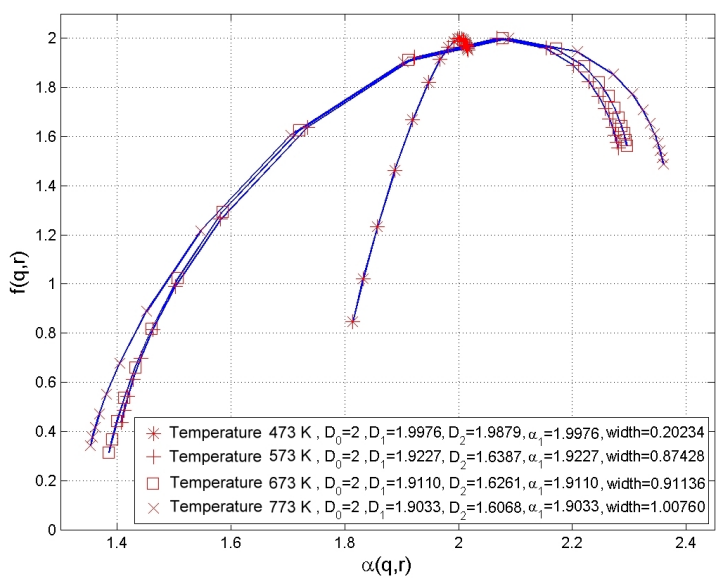

Fig. 3. Multifractal singularity spectrum $f(\alpha)$ of TiN layers grown at (a) $473 \mathrm{~K}$, (b) $573 \mathrm{~K}$, (c) $673 \mathrm{~K}$, and (d) $773 \mathrm{~K}$, with the generalized dimensions $\mathrm{D}_{\mathrm{q}}$ for $\mathrm{q}=0,1,2$, for scanning square area of $1 \mu \mathrm{m} \times 1 \mu \mathrm{m}$.

The smoothest surface, corresponding to the lowest values of height parameters ( $\mathrm{Sq}, \mathrm{Sp}, \mathrm{Sv}, \mathrm{Sz}$ and $\mathrm{Sa}$ ), functional parameters, hybrid parameters, and functional parameters (volume), was found in the TiN layers grown at $473 \mathrm{~K}$. The others TiN layers grown at $573 \mathrm{~K}, 673 \mathrm{~K}$ and $773 \mathrm{~K}$, have different values of the statistical parameters, all higher than the corresponding values obtained at $473 \mathrm{~K}$. Our results suggest that the surface morphology of (TiN) thin films, prepared by reactive DC magnetron sputtering, gets textured with an increase in temperature of the substrate, and can be tailored to particular morphologies. According to Bavadi et al. [35], TiN thin films have the grains preferentially oriented along (101), (200) between 43 and 44 degree. On the other hand, the obtained values are in good agreement with the experimental and theoretical results reported in the literature $[35,36]$, confirming the overall quality of the data reduction procedure.

\section{Conclusions}

TiN thin films have been prepared at different temperatures of substrate by reactive DC magnetron sputtering. Their surface morphologies obtained from AFM images were subjected to statistical and multifractal analysis to quantitatively investigate their structural properties. The three important multifractal parameters $\mathrm{D}_{\mathrm{q}}, \Delta \alpha$ and $\Delta \mathrm{f}$ were calculated to describe the multifractal nature of the 3-D samples surfaces. AFM images show the nanostructure of the thin films with varying surface topography and increasing surface roughness upon increasing the substrate temperature. The morphology of the analyzed samples provides a more complete description of the structural features that can contribute to subsequent integration into the nanotribology processes, from both theoretical and experimental perspectives. Statistical parameters and multifractal analysis are valuable approaches to study the AFM images of surface topography of (TiN) thin films prepared by reactive DC magnetron sputtering. The multifractal behavior also can be used to develop 3-D mathematical models, which helps to study the 3-D grow processes on TiN layers.

\section{References}

[1] Ţălu Ş., Ghazai A.J., Stach S., Hassan A., HaSSAN Z., ŢĂLU M., J. Mater. Sci.-Mater. El., 25 (1) (2014), 466.

[2] Dallaeva D., Ţălu Ş., Stach S., ŠKarVada P., TománeK P., Grmela L., Appl. Surf. Sci., 312 (2014), 81.

[3] Stach S., Dallaeva D., ŢĂlu Ş., Kaspar P., Tománek P., Giovanzana S., Grmela L., Mater. Sci.-Poland, 33 (1) (2015), 175.

[4] Ţălu Ş., Stach S., Solaymani S., Moradian R., Ghaderi A., Hantehzadeh M.R., Elahi S.M., GARCZYK Ż., IZADYAR S., J. Electroanal. Chem., 749 (2015), 31.

[5] Chou W.J., Yu G.P., Huang J.H., Surf. Coat. Tech., 140 (3) (2001), 206.

[6] Chou W.J., Yu G.P., Huang J.H., Surf. Coat. Tech., 149 (2002), 7.

[7] Oettel H., Wiedemann R., Preibler S., Surf. Coat. Tech., 74 - 75 (1) (1995), 273.

[8] Cheng Z., Peng H., XIE G., Shi Y., Surf. Coat. Tech., $138(2-3)$ (2001), 237.

[9] Tamura M., Kubo H., Surf. Coat. Tech., 49 (1 - 3) (1991), 194. 
[10] Almtoft K.P., Structural characterization of nanocrystalline thin films grown by magnetron sputtering, PhD Thesis, University of Aarhus, Denmark, 2006.

[11] Steenbeck K., Steinbeib E., Ufert K.D., Thin Solid Films, 92 (4) (1982), 371.

[12] Ellmer K., Mientus R., Reactive DC magnetron sputtering of elemental targets in Ar/O2-mixtures: relation between the discharge characteristics and the heat of formation of the corresponding oxides, in: HECHT R. (Ed.), Thin films: proceedings of the joint 4. international symposium on trends and new applications in thin films - TATF '94 and the 11. conference on high vacuum, interfaces and thin films - HVITF '94. [S.l.], Dresden, Germany, 1994, p. 131.

[13] HOFMANN S., Thin Solid Films, 193 - 194 (2) (1990), 648.

[14] MIENTUS R., ELLMER K., Surf. Coat. Tech., 116 119 (1990), 1093.

[15] MountainsMap®7 Software (Digital Surf, Besançon, France), available from: http://www.digitalsurf . fr (last accessed May $\left.20^{\text {th }}, 2015\right)$.

[16] ISO 25178-2:2012, Geometrical product specifications (GPS) - Surface texture: Areal - Part 2: Terms, definitions and surface texture parameters, available from: http: //www. iso.org (last accessed May 20 $0^{\text {th }}, 2015$ ).

[17] ŢĂLU Ş., Stach S., Polym Eng. Sci., 54 (5) (2014), 1066.

[18] ŢăLu Ş., Marković Z., Stach S., Marković B.T., ŢĂLU M., Appl Surf Sci., 289 (2014), 97.

[19] ŢĂLu Ş., Stach S., MÉndez A., Trejo G., ŢăLU M., J. Electrochem. Soc., 161 (2014), D44.

[20] Ţălu Ş., Stach S., Mahajan A., Pathak D., WaGNer T., Kumar A., Bedi R.K., ŢĂLU M., Electron. Mater. Lett., 10 (4) (2014), 719.

[21] Ţălu Ş., Stach S., Mahajan A., Pathak D., WagNER T., KUMAR A., BEDI R.K., Surf. Interface Anal., 46 (6) (2014), 393.
[22] Stach S., Cybo J., Cwajna J., Roskosz S., Mater. Sci.-Poland, 23 (2005), 583.

[23] ŢăLu Ş., Anim. Biol. Anim. Husb., 4 (2012), 1.

[24] ŢĂLU Ş., ELBA Bioflux, 4 (2012), 8.

[25] Turiel A., Perez-Vicente C.J., Grazzini J., J. Comput. Phys., 216 (2006), 362.

[26] Ţălu Ş., Stach S., Ghodselahi T., Ghaderi A., Solaymani S., Boochani A., Garczyk Ż., J. Phys. Chem. B, 119 (17) (2015), 5662.

[27] KINSNER W., JITR, 1 (4) (2008), 62.

[28] KWaśny W., J. Achiev. Mater. Manuf. Eng., 2 (37) (2009), 125.

[29] Stach S., Roskosz S., Cybo J., Cwajna J., Mater. Charact., 60 (2009), 1151.

[30] Chhabra A., Jensen R.V., Phys. Rev. Lett., 62 (1989), 1327.

[31] Yadav R.P., Dwivedi S., Mittal A.K., Kumar M., PANDEY A.C., Appl. Surf. Sci., 261 (2012), 547.

[32] Ţălu Ş., Stach S., Zaharieva J., Getsova M, Elenkova D., Milanova M., Int. J. Polym. Anal. Ch., 19 (7) (2014), 648.

[33] Elenkova D., Zaharieva J., Getsova M., Manolov I., Milanova M., Stach S., Ţălu Ş., Int. J. Polym. Anal. Ch., 20 (1) (2015), 42.

[34] GaphPad InStat software, version 3.20 (GraphPad, San Diego, CA), available from: http://www.graphpad. com/instat/instat.htm (last accessed May $20^{\text {th }}$, 2015).

[35] Bavadi R., Valedbagi S., Mater. Phys. Mech., 15 (2012), 167.

[36] Ţălu Ş., Stach S., Valedbagi S., Elahi S.M., BAVADI R., Mater. Sci.-Poland, 33 (1) (2015), 137.

Received 2014-11-01 Accepted 2015-05-22 